Authors:

Jorge Gonzalez Cataloging Liaison
Suzanne Stapleton

Agricultural Sciences \&

Digital Scholarship Librarian
Ann Baird

Design Librarian,

Architecture and Fine Arts Library
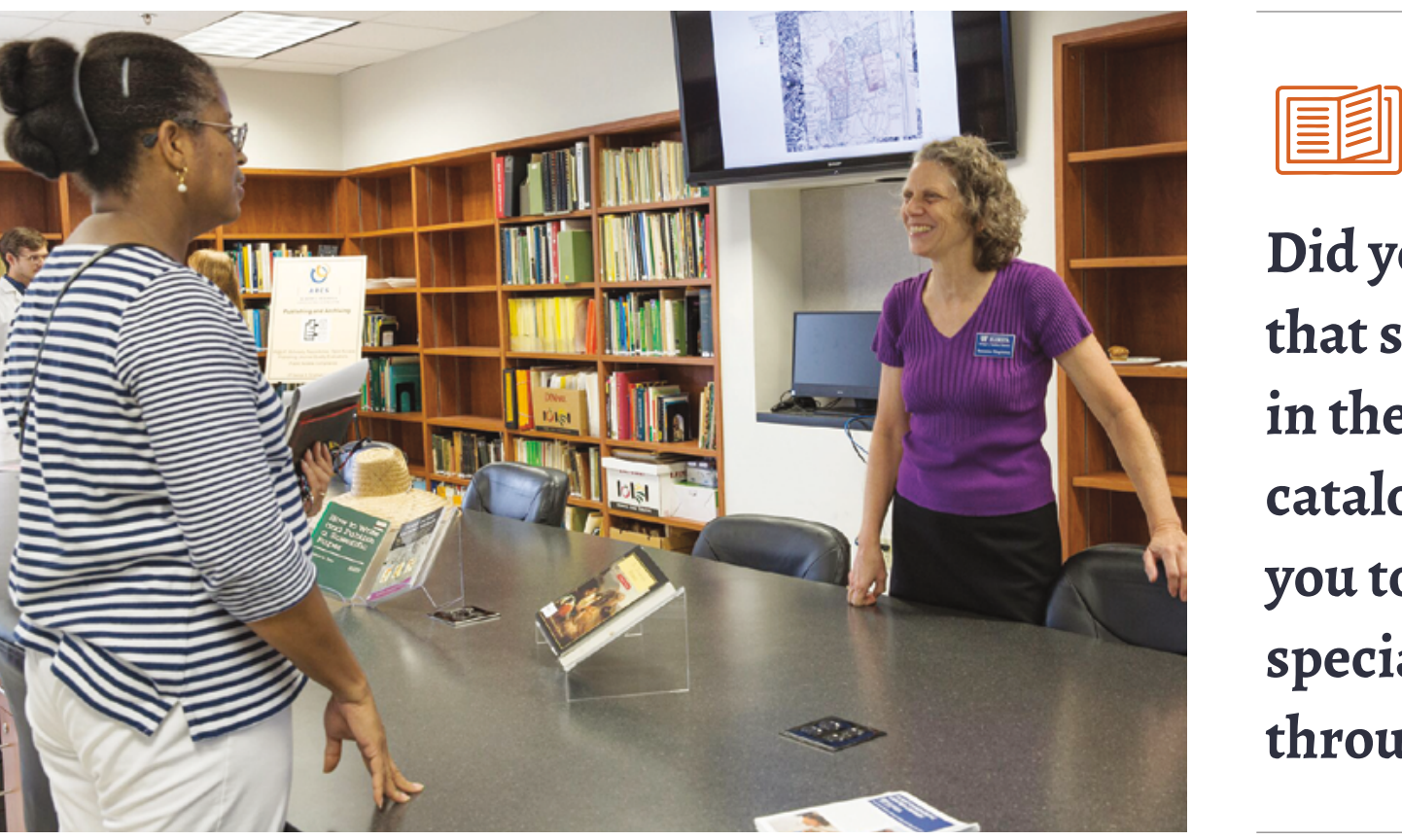

Did you know that searches in the UF library catalog may lead you to discover specialized collections throughout the state?

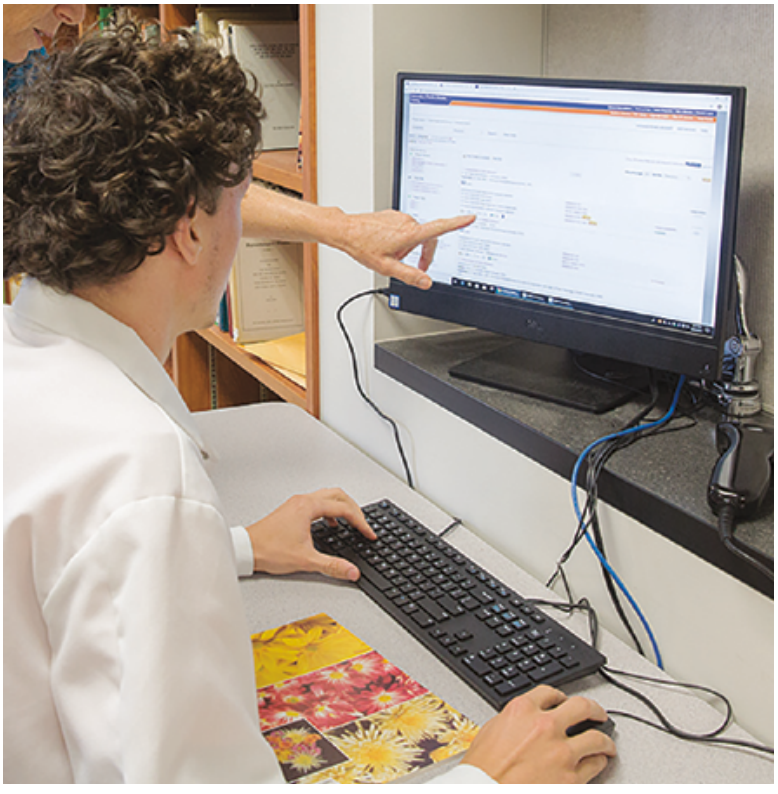

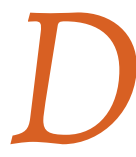

igital access to library content can transport us nearly anywhere. Yet still it feels good to be in a library - the physical space set aside for learning. To hold a book in hand, scan a bookshelf for related titles that catch your interest, or strike up conversation with a fellow scholar can lead to unexpected serendipity. Flipping through the architectural designs of Floating Houses: Living Over the Water (Martinez, 2018), for instance, the imagination is unmoored to reconsider sustainable living that can move with the tides.

Leafing through the pages of a Compendium of Crop Diseases might remind you why they say a picture is worth a thousand words. The American Phytopathological Society publishes this picture-laden series of booklets of diseases that infect over 25 crops grown in Florida. In the University of Florida Institute of Food \& Agricultural 


\section{Greg Allen}

Cataloging Liaison

C When the LGBTQ Library was started as an affiliate library in the Rainbow

Room in Peabody Hall many years ago,

I was enlisted to train the staff there on how to use our catalog system so that their collection of books and videos would show in our online catalog. This included creating holdings for titles already in the catalog, as well as importing records from OCLC [a shared national cataloging resource] for titles that didn't yet have a presence in the UF library. I also donated several LGBTQ themed books from my home to add to their collection. I plan to continue the training now that our library has begun using a library management system."

\section{TAMARA COHEN LGBTQ RESOURCE CENTER LIBRARY}

Sexual orientation was added to the University's anti-discrimination policy in 2003. The following year an inclusive diversity policy was adopted and the Office of LBGT Affairs opened with Tamara Cohen as Director. As favorite and influential books were shared, a collection began to take shape. L.B. Hannahs, then LGBT Affairs Director, launched this affiliated library in 2012 in the Rainbow Room in Peabody Hall. Greg Allen, in the Smathers Libraries Cataloging and Discovery Services department assisted with cataloging the materials. Now located in the LGBTQ+ Affairs office in J. Wayne Reitz Union Suite 2210, this collection of nearly 800 titles supports the various multidisciplinary LGBTQ-related programs on campus.

Materials range from poetry and fiction to nonfiction legal summaries, histories, and handbooks for affirming diverse campuses. Titles address the intersection of gender identity with racial, cultural, and other biases. Unique titles expand the main library's collection to include Gloria Steinem's Revolution from Within: a Book of Self-esteem (1992), The Love Songs of Sappho (1998), and the Advocate College Guide for LBGT Students (2006). The Tamara Cohen LGBTQ+ Resource Center Library offers a safe space for respite and reflection in the convenience of the student union.

https://lgbtq.multicultural.ufl.edu/programs/ tamara-cohen-resource-library/
Each affiliated library provides their own staff to caretake their collection. These caretakers have broad knowledge of the specific subject matter of the library's holdings and implement best collection management practices. The affiliated libraries' caretaker keeps up to date on the latest information technology and consults with the Smathers Libraries on newly developed bibliographic instructions and changes to cataloging rules and procedures. Library caretakers promote their collections, provide reference assistance, and develop local circulation policies.

Smathers Libraries support these collections with a cataloging liaison, a subject specialist liaison, and the Affiliated Libraries Working Group. Jorge Gonzalez is the cataloging liaison who helps most affiliated libraries add materials to the library database, install cataloging software, and train staff. Subject specialist liaison librarians provide bibliographic instruction to affiliate staff and their local researchers.

Even as digital content dominates libraries today, the affiliated library program enables specialized physical collections to be listed in the library catalog and used in creative ways throughout the state. If you find yourself nearby one of our affiliated libraries, you're invited to stop in and browse! $\mathbf{S}$

For more info including a list

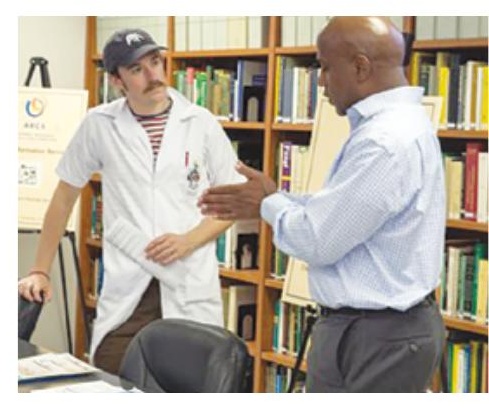
of all Affiliated Libraries contact info and hours:

https://uflib.ufl.edu/

libraries-collections/affiliated/ 